\title{
Relationship between childhood trauma and level of insight in schizophrenia: a path-analysis in the national FACE-SZ dataset
}

Baptiste Pignon $^{\mathrm{a}, \mathrm{i}}$, MD, Mohamed Lajnef, Msc, Ophélia Godina ${ }^{\mathrm{a}}, \mathrm{PhD}$, Marie-Maud Geoffray ${ }^{\mathrm{a}}$, MD, Romain Rey ${ }^{\mathrm{a}}$, MD, Jasmina Mallet ${ }^{\mathrm{a}}, \mathrm{MD}$, Caroline Dubertret ${ }^{\mathrm{a}, 1}, \mathrm{MD}, \mathrm{PhD}$, Paul Roux $^{\mathrm{a}, \mathrm{b}, \mathrm{c}}, \mathrm{MD}, \mathrm{PhD}$, Christine Passerieux ${ }^{\mathrm{a}, \mathrm{b}, \mathrm{c}}, \mathrm{MD}, \mathrm{PhD}$, Laurent Marulaz ${ }^{\mathrm{a}, \mathrm{i}}, \mathrm{MD}$, Lore Brunel $^{\mathrm{a}, \mathrm{i}}$, Msc, Julien Dubreucq ${ }^{\mathrm{a}, \mathrm{m}}$, MD, Sylvain Leignier ${ }^{\mathrm{a}, \mathrm{m}}$, MD, Delphine Capdevielle ${ }^{\mathrm{a}, \mathrm{f}}$, MD, PhD, Myrtille André ${ }^{\mathrm{a}, \mathrm{f}}$, MD, Bruno Aouirzerate ${ }^{\mathrm{a}, \mathrm{d}, \mathrm{g}}, \mathrm{MD}, \mathrm{PhD}$, David Misdrahi ${ }^{\mathrm{a}, \mathrm{d}, \mathrm{e}}, \mathrm{MD}$, $\mathrm{PhD}$, Fabrice Berna ${ }^{\mathrm{a}, \mathrm{h}}, \mathrm{MD}, \mathrm{PhD}$, Pierre Vidailhet ${ }^{\mathrm{a}, \mathrm{h}}, \mathrm{MD}, \mathrm{PhD}$, Isabelle Chereau ${ }^{\mathrm{a}, \mathrm{j}}, \mathrm{MD}, \mathrm{MD}$, PhD, Pierre-Michel Llorca ${ }^{\mathrm{a}, \mathrm{j}}, \mathrm{MD}, \mathrm{PhD}$, Guillaume Fond ${ }^{\mathrm{a}, \mathrm{n}}, \mathrm{MD}, \mathrm{PhD}$, Christophe Lançon ${ }^{\mathrm{a}, \mathrm{n}}$, MD, PhD, Marion Leboyer ${ }^{\mathrm{a}, \mathrm{i}}, \mathrm{MD}, \mathrm{PhD}$, Franck Schürhoffa, ${ }^{\mathrm{a}, \mathrm{MD}}, \mathrm{PhD}$, and the FondaMental Academic Centers of Expertise for Schizophrenia (FACE-SZ) collaborators*

Affiliations :

${ }^{\text {a}}$ Fondation Fondamental, Créteil, France

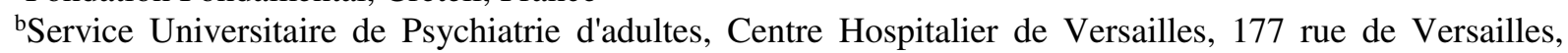
78157 Le Chesnay, France

'Laboratoire HandiRESP, EA4047, UFR des sciences de la santé Simone Veil, Université de Versailles Saint-Quentin-En-Yvelines, 2 Avenue de la Source de la Bièvre, 78180 Montigny-le-Bretonneux, France ${ }^{\mathrm{d} C e n t r e ~ H o s p i t a l i e r ~ C h a r l e s ~ P e r r e n s, ~ F-33076 ~ B o r d e a u x, ~ F r a n c e ; ~ U n i v e r s i t e ́ ~ d e ~ B o r d e a u x, ~ F r a n c e ~}$ ${ }^{\mathrm{e}}$ CNRS UMR 5287-INCIA, France

fService Universitaire de Psychiatrie Adulte, Hôpital la Colombière, CHRU Montpellier, Université Montpellier 1, Inserm 1061, Montpellier, France

gInserm, Neurocentre Magendie, Physiopathologie de la Plasticité Neuronale, U862, F-33000 Bordeaux, France

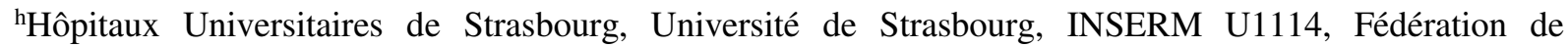
Médecine Translationnelle de Strasbourg, Strasbourg, France

iINSERM U955, Translational Psychiatry team, Créteil, France, Université Paris-Est Créteil (UPEC), APHP, DHU Pe-PSY, Pôle de Psychiatrie des Hôpitaux Universitaires H Mondor, Créteil, France

${ }^{j}$ CMP B, CHU, EA 7280 Faculté de Médecine, Université d'Auvergne, BP 6963003 Clermont-Ferrand Cedex 1, France

${ }^{k}$ Université Claude Bernard Lyon 1/Centre Hospitalier Le Vinatier Pole Est BP 30039 - 95 bd Pinel 69678 BRON Cedex, France

${ }^{1}$ AP-HP, Department of Psychiatry, Louis Mourier Hospital, Colombes, Inserm U894, Université Paris Diderot, Sorbonne Paris Cité, Faculté de médecine, France

${ }^{\mathrm{m}}$ Centre Référent de Réhabilitation Psychosociale, $\mathrm{CH}$ Alpes Isère, Grenoble, France

${ }^{\mathrm{n}}$ Assistance Publique des Hôpitaux de Marseille (AP-HM), pôle universitaire de psychiatrie, Marseille, France

*Members and affiliations of the FACE-SCZ Group:

Andrianarisoa MD ${ }^{\mathrm{l}}$, MD; Aouizerate $\mathrm{B}^{\mathrm{a}, \mathrm{l}}$, MD, PhD; Berna $\mathrm{F}^{\mathrm{b}, \mathrm{l}}, \mathrm{MD}$, PhD; Blanc $\mathrm{O}^{\mathrm{c}, 1}$, Msc; Brunel $\mathrm{L}^{\mathrm{d}, \mathrm{l}}$, Msc; Bulzacka Ed,l, Msc; Capdevielle De,l, MD, PhD; Chereau-Boudet Ic,l, MD; Chesnoy-Servanin G ${ }^{\mathrm{f}, 1}$, 
Msc; Danion Jm ${ }^{\mathrm{b}, \mathrm{l}}$, MD; D’Amato $\mathrm{T}^{\mathrm{f}, 1}, \mathrm{MD}, \mathrm{PhD}$; Deloge $\mathrm{A}^{\mathrm{g}, 1}$, MD, PhD; Delorme $\mathrm{C}^{\mathrm{h}, \mathrm{l}}$, Msc; Denizot $\mathrm{H}^{\mathrm{c}, \mathrm{l}}$, MD; Dorey JM ${ }^{\mathrm{f}, 1}, \mathrm{MD}$; Dubertret $\mathrm{C}^{\mathrm{i}, 1}, \mathrm{MD}$, PhD; Dubreucq J ${ }^{\mathrm{h}, 1}$, MD; Faget $\mathrm{C}^{\mathrm{j}, 1}, \mathrm{MD}$; Fluttaz $\mathrm{C}^{\mathrm{h}, \mathrm{l}}, \mathrm{Msc}$; Fond $\mathrm{G}^{\mathrm{d}, \mathrm{l}}$, MD; Fonteneau $\mathrm{S}^{\mathrm{k}, \mathrm{l}}$, Msc; Gabayet $\mathrm{F}^{\mathrm{h}, \mathrm{l}}$, Msc; Giraud-Baro $\mathrm{E}^{\mathrm{h}, \mathrm{l}}, \mathrm{MD}$; Hardy-Bayle MC ${ }^{\mathrm{k}, \mathrm{l}}, \mathrm{MD}, \mathrm{PhD}$; Lacelle $\mathrm{D}^{\mathrm{c}, \mathrm{l}}$, Msc; Lançon $\mathrm{C}^{\mathrm{j}, 1}, \mathrm{MD}$, PhD; Laouamri $\mathrm{H}^{\mathrm{l}}$, Msc; Leboyer $\mathrm{M}^{\mathrm{d}, 1}$, MD, PhD; Le Gloahec $\mathrm{T}^{\mathrm{d}, \mathrm{l}}$, Msc; Le Strat $Y^{\mathrm{i}, 1}, \mathrm{MD}, \mathrm{PhD}$; Llorca ${ }^{\mathrm{c}, \mathrm{l}} \mathrm{PM}, \mathrm{MD}, \mathrm{PhD}$; Mallet $\mathrm{J}^{\mathrm{i}, 1}$, MD, PhD; Metairie $\mathrm{E}^{\mathrm{j}, 1}$, Msc; Misdrahi $\mathrm{D}^{\mathrm{g}, 1}, \mathrm{MD}$; Offerlin-Meyer I ${ }^{\mathrm{b}, \mathrm{l}}, \mathrm{PhD}$; Passerieux $\mathrm{C}^{\mathrm{k}, \mathrm{l}}$, MD, PhD; Peri $\mathrm{P}^{\mathrm{j}, 1}, \mathrm{Msc}$; Pires $\mathrm{S}^{\mathrm{c}, \mathrm{l}}$, Msc; Portalier $\mathrm{C}^{\mathrm{i}, 1}$, Msc; Rey $\mathrm{R}^{\mathrm{f}, \mathrm{l}}$, MD; Roman $\mathrm{C}^{\mathrm{h}, \mathrm{l}}$, Msc; Sebilleau $\mathrm{M}^{\mathrm{k}, \mathrm{l}}$, Msc; Schandrin $\mathrm{A}^{\mathrm{e}, \mathrm{l}}$, MD; Schurhoff $\mathrm{F}^{\mathrm{d}, \mathrm{l}}, \mathrm{MD}, \mathrm{PhD}$; Tessier A $A^{\mathrm{g}, 1}$, Msc; Tronche Am ${ }^{\mathrm{c}, 1}$, MD; Urbach $\mathrm{M}^{\mathrm{k}, 1}$, MD; Vaillant $\mathrm{F}^{\mathrm{j}, 1}$, Msc; Vehier $\mathrm{A}^{\mathrm{f}, 1}$, Msc; Vidailhet $\mathrm{P}^{\mathrm{b}, \mathrm{l}}$, MD, PhD; Vilà E ${ }^{\mathrm{g}, 1}, \mathrm{Msc}$; Yazbek $\mathrm{H}^{\mathrm{e}, 1}, \mathrm{PhD}$; Zinetti-Bertschy A $\mathrm{A}^{\mathrm{b}, \mathrm{l}}$, Msc

${ }^{a}$ Centre Hospitalier Charles Perrens, F-33076 Bordeaux, France; Université de Bordeaux, Inserm, Neurocentre Magendie, Physiopathologie de la Plasticité Neuronale, U862, F-33000 Bordeaux, France

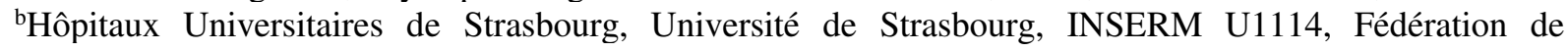
Médecine Translationnelle de Strasbourg, Strasbourg, France

${ }^{\circ}$ CMP B, CHU, EA 7280 Faculté de Médecine, Université d'Auvergne, BP 6963003 Clermont-Ferrand Cedex 1, France

${ }^{\text {d} A P-H P, ~ D H U ~ P e-P S Y, ~ P o ̂ l e ~ d e ~ P s y c h i a t r i e ~ e t ~ d ' a d d i c t o l o g i e ~ d e s ~ H o ̂ p i t a u x ~ U n i v e r s i t a i r e s ~ H ~}$ Mondor,INSERM U955, Eq 15 Psychiatrie Translationelle, , Université Paris Est-Créteil, Créteil, France

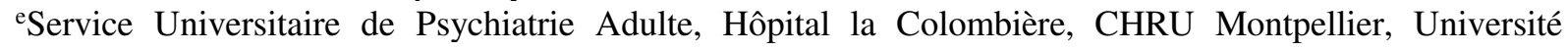
Montpellier 1, Inserm 1061, Montpellier, France

fUniversité Claude Bernard Lyon 1/Centre Hospitalier Le Vinatier Pole Est BP 30039 - 95 bd Pinel 69678 BRON Cedex, France

${ }^{\mathrm{g}}$ Centre Hospitalier Charles Perrens, F-33076 Bordeaux, France; Université de Bordeaux, CNRS UMR 5287-INCIA, France

${ }^{\text {h} C e n t r e ~ R e ́ f e ́ r e n t ~ d e ~ R e ́ h a b i l i t a t i o n ~ P s y c h o s o c i a l e, ~} \mathrm{CH}$ Alpes Isère, Grenoble, France

iAP-HP, Department of Psychiatry, Louis Mourier Hospital, Colombes, Inserm U894 Université Paris Diderot, Sorbonne Paris Cité, Faculté de médecine, France

${ }^{j}$ Assistance Publique des Hôpitaux de Marseille (AP-HM), pôle universitaire de psychiatrie, Marseille, France

${ }^{\mathrm{k} S e r v i c e}$ de psychiatrie d'adulte, Centre Hospitalier de Versailles, Le Chesnay, EA 4047 HANDIReSP, UFR des Sciences de la Santé Simone Veil, Université Versailles Saint-Quentin en Yvelines, Versailles, France

${ }^{1}$ Fondation Fondamental. 


\section{ABSTRACT}

\section{Introduction}

This study aimed was to investigate the relationship between different types of childhood trauma and the level of insight (i.e., awareness of having a psychiatric disorder) in subjects suffering from schizophrenia, as well as the putative role of clinical mediators.

\section{Methods}

294 community-dwelling subjects with stable schizophrenia were included into FACE-SZ, a multicentre cross-sectional study. All patients were assessed by specialized multidisciplinary teams. The level of insight was assessed by the Scale to assess Unawareness of Mental Disorder (SUMD), and childhood trauma by the Childhood Trauma Questionnaire (CTQ).

Path analyses from the five CTQ subscales (physical abuse and neglect, emotional abuse and neglect, and sexual abuse) and the SUMD, with current symptomatology (i.e., positive, negative, global psychopathology and depression) as mediator, was performed.

\section{Results}

Physical neglect $(\beta=0.14)$ and abuse $(\beta=0.13)$ were significantly associated with poor insight. Negative symptoms were a clinical mediator of the relationship between physical neglect and poor insight. Moreover, positive $(\beta=0.21)$ and negative $(\beta=0.30)$ symptoms were associated with poor insight, whereas depression $(\beta=-0.14)$ was associated with higher levels of insight.

\section{Discussion}

For the first time, this study shows a significant relationship between childhood trauma, specifically physical neglect and abuse, and poor insight. The level of insight was linked to different clinical dimensions. Among subjects with schizophrenia, these results provide support for a role of childhood trauma in poorer management outcomes, and the need to provide treatment, including psycho-education that better targets the consequences of childhood trauma.

Key-words: Schizophrenia, Childhood trauma, insight, negative symptoms, path-analysis 


\section{INTRODUCTION}

Poor insight is defined as the presence of an impaired awareness of having a psychiatric disorder, as well as of its symptoms and implications. Poor insight has been reported in 50 to $80 \%$ of patients with schizophrenia (Lincoln et al., 2007). A low level of insight is associated with negative attitudes towards taking antipsychotic medication, and to the decision to decline treatments (Lysaker et al., 2018). Similarly, it is associated with higher rates of rehospitalisation and poor global functioning (Lysaker et al., 2018; Pousa et al., 2017). Moreover, several studies have shown that poor insight is associated with the overall severity of schizophrenia, and in particular with positive, negative and disorganisation symptoms (Amador et al., 1994; Brohan et al., 2010; Mintz et al., 2003; Zhou et al., 2015). Conversely, high levels of insight are associated with depression, self-stigma, and suicidality (Misdrahi et al., 2014; Schrank et al., 2014). Finally, insight appears to be temporally stable (Cuesta et al., 2000; Smith et al., 2004), with cognitive-behavioural and psycho-education therapies having a significant (but small to moderate) positive effect on insight levels (Pijnenborg et al., 2013).

Childhood trauma (CT) is defined by a range of severe adverse experiences, including physical, sexual and emotional abuse, neglect, or bullying. These experiences may affect approximately one-third of the general population (Kessler et al., 2010; Scher et al., 2004). There is an accumulating body of evidence suggesting an association between such CT experiences and a range of negative social and health outcomes, including higher gastrointestinal disorders, chronic pelvic pain, and cardiometabolic disorders, as well as several psychiatric disorders (McLaughlin et al., 2010; Paras et al., 2009; Tebeka et al., 2016;

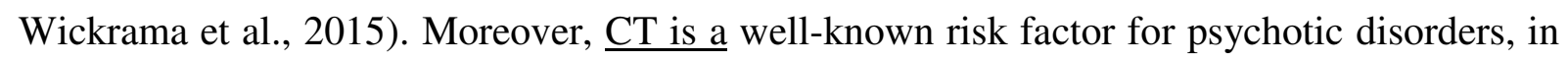
interaction with genetic risk, and in an addition of other environmental risk factors, such as urbanicity, or cannabis use (Guloksuz and van Os, 2018; Kraan et al., 2018; Pries et al., 2018; Varese et al., 2012). Some studies have even suggested a dose-dependent relationship between CT and psychosis (Schäfer and Fisher, 2011). More specifically, sexual and physical abuse (Fisher et al., 2009; Shevlin et al., 2008), separation from the parents (Baudin et al., 2017; Morgan et al., 2007), and peer-victimisation or bullying (Trotta et al., 2013) are associated with future psychotic disorders. Moreover, among patients with psychotic disorders, CT are identified as modifier factors, i.e., factors that are associated with specific clinical features or specific course of the disease (Misiak et al., 2017). For instance, several studies showed associations between CT history and more severe positive symptoms (Duhig 
et al., 2015; McCabe et al., 2012; Read et al., 2005; Schalinski et al., 2015), in particular auditory-verbal hallucinations (Bailey et al., 2018; Bentall et al., 2012). Interestingly, among patients with bipolar disorders, childhood abuse was also associated with the presence of auditory-verbal hallucinations (Smith et al., 2017). Consistent with these results, recent studies in the FACE-SZ dataset show $\underline{\mathrm{CT}}$ to be associated with the number of hospitalizations, and worse overall outcome, as well as positive, and negative psychotic symptoms, and low global functioning (Andrianarisoa et al., 2017; Baudin et al., 2016; Roux et al., 2018).

CT may have a negative impact on insight levels, and clinical mediators may be involved. However, the specific impact of CT on the level of insight has never been studied. Moreover, studying the associations between CT, clinical dimensions and insight could help to define subsets of patients for whom specific interventions, such as psychotherapy, may be of utility. This study uses path-analysis methods to investigate factors modulating insight levels. We hypothesise that CT could be negatively associated with insight in schizophrenia. This association may be both direct and indirect, and partly mediated by positive and negative symptoms dimensions. As such, this study aims was to analyse the relationship between CT and insight, in association with several clinical dimensions, in a sample of patients with schizophrenia. 


\section{METHODS}

\section{The FACE-SZ dataset}

Subjects over 18 years-old with schizophrenia or schizo-affective disorder according to DSM-IV-TR have been included through the FACE-SZ (FondaMental Advanced Centre of Expertise - Schizophrenia) network. FACE-SZ is a French national multicentre network of ten schizophrenia expert centres (Bordeaux, Clermont-Ferrand, Colombes, Créteil, Grenoble, Lyon, Marseille, Montpellier, Strasbourg, Versailles) of the FondaMental foundation (https://www.fondation-fondamental.org/). They provide a detailed evaluation and suggest therapeutic interventions. Patients are referred by their general practitioner or psychiatrist. A web application (e-schizo $($ ) $)$ is used to record data in a common computerized medical file. Anonymized data was entered into a shared national database for use in multi-centre audit and research (Schürhoff et al., 2015).

\section{Collected data}

All patients were assessed by the specialized multidisciplinary team of the Expert centres. A large standardized clinical evaluation was used to determine diagnosis, comorbidities, severity, and other specific variables (Schürhoff et al., 2015).

Insight was assessed using the French version of the Scale to assess Unawareness of Mental Disorder (SUMD), a clinician-rated instrument (Raffard et al., 2010). The SUMD is a standardised rating-scale based on a patient interview. It assesses the current awareness of the 9 following states: 1) a mental disorder, 2) consequences of a mental disorder, 3) effects of drugs, 4) hallucinations, 5) delusional ideas, 6) disorganised thoughts, 7) blunted affect, 8) anhedonia, and 9) lack of sociability. SUMD utilizes three Likert-scale response levels (0: aware, 1: slightly aware/unaware, 2: severely unaware). We used the total SUMD score linearized on a scale of 0 to 100, with 100 representing the highest level of unawareness. The construct validity, the reliability and the external validity of scale have been studied by Michel et al. (2013). Cronbach's alpha coefficients ranged from 0.76 to 0.83 for the 9 items, indicating satisfactory reliability. The inter-rater reliability was also satisfactory, with items ranging from 0.68 to 1.00 (Raffard et al., 2010).

CT was assessed with the French version of the Childhood Trauma Questionnaire (CTQ), a 25-items questionnaire. All items are answered on a five-point Likert-scale (1: 
never, to 5: very often). The CTQ provides one total score, and five sub-scores: physical abuse, emotional abuse, sexual abuse, physical neglect, and emotional neglect. The CTQ total score is the sum of all items (Bernstein et al., 2003; Paquette et al., 2004).

Current symptomatology was assessed with the Positive and Negative Symptoms Scale (PANSS), and its 3 sub-scores: positive, negative, and global psychopathology symptoms. Depressive symptoms were assessed by the Calgary Depression Rating Scale for Schizophrenia (CDSS).

\section{Ethical approval}

The study was carried out in accordance with ethical principles for medical research involving humans (WMA, Declaration of Helsinki). The assessment protocol was approved by the relevant ethical review board (CPP-Ile de France IX, January 18th, 2010). All data were collected anonymously. As this study included data from regular care assessments, a non-opposition form was signed by all participants. Approval for access to the system was was obtained from the committee in charge of the safety of computerized databases (CNIL, number DR-2011-069).

\section{Statistical analyses}

The data were analysed in a path-analysis using Maximum Likehood estimation with Robust standard errors (MLR) (version 6.1) (Muthén and Muthén, 2007). Path analyses from the 5 five subscales of the CTQ, with the clinical variables (CDSS measured depression, and the 3 subscales of the PANSS: positive, negative, and general psychopathology) as mediators, to the score of insight (SUMD) were performed. An iterative procedure allowed the selection of the best-fitting model. The path-analysis started with a saturated model in which all variables were interrelated. Then, non-significant path correlations/associations were gradually excluded until a good-fitting model was reached. The overall model fit was examined using the Chi-square statistic, the Comparative Fit Index (CFI) and the Root Mean Square Error of Approximation (RMSEA). The rules of thumb for determining acceptable model fit were as follows: a non-significant Chi-square test, a CFI value of 0.90 or above, and RMSEA values close to 0.05 or below. All path coefficients and correlations are reported as standardized estimates.

The model examined both direct and indirect associations between the CT subscales and the SUMD. The model also examined the correlations of the $5 \mathrm{CT}$ subscales and putative 
clinical mediating variables, as well as estimating correlations among the 5 CTQ sub-scales. A path diagram representation of the model was then drawn: straight single-headed arrows representing regression paths, and curved tow-headed arrows representing correlations. 


\section{RESULTS}

\section{Characteristics of the sample}

A total of 294 community-dwelling stable patients with schizophrenia were included (74\% male), with a mean age at interview of 32.1 years ( \pm 9.8 years). The main sociodemographic and clinical characteristics of the sample are available in Table $\mathbf{1 .}$

\section{- TABLE 1 -}

\section{Statistical associations of variables}

Here we report only the significant direct associations between i) the different types of trauma and putative mediator variables, and ii) the putative mediator variables and the SUMD. Physical neglect and sexual abuse were associated with higher levels of positive symptoms (physical neglect: $\beta=0.14$, standard-error $(\mathrm{SE})=0.06$ and $\mathrm{p}=0.02$, sexual abuse: $\beta=0.18, \mathrm{SE}=0.08$ and $\mathrm{p}=0.03$ ) and of global psychopathology symptoms (physical neglect: $\beta=0.20, \mathrm{SE}=0.06$ and $\mathrm{p}<0.01$, sexual abuse: $\beta=0.19, \mathrm{SE}=0.09$ and $\mathrm{p}=0.03$ ). Physical abuse was associated with a high level of negative symptoms $(\beta=0.14, \mathrm{SE}=0.05$ and $\mathrm{p}<$ $0.01)$ and a low level of depression $(\beta=-0.12, \mathrm{SE}=0.06$ and $\mathrm{p}<0.05)$. This is in contrast to emotional abuse, which was associated with lower levels of negative symptoms $(\beta=-0.14, \mathrm{SE}$ $=0.05$ and $\mathrm{p}=0.04)$ and $\underline{\text { raised levels }}$ of depression $(\beta=0.17, \mathrm{SE}=0.08$ and $\mathrm{p}=0.03)$. Emotional neglect was associated with a high level of depression $(\beta=0.17, \mathrm{SE}=0.08$ and $\mathrm{p}=$ 0.02). Positive and negative symptoms were associated with low levels of insight, as indicated by a high SUMD scale score: $\beta=0.21, \mathrm{SE}=0.07$ and $\mathrm{p}<0.01$ for positive symptoms; $\beta=$ $0.29, \mathrm{SE}=0.07$ and $\mathrm{p}<0.001$ for negative symptoms. The different sub-scores of CT were correlated. We did not find any direct association between the different types of trauma and level of insight. Of the considered mediator factors, none showed a significant mediation between the CT subscales and insight. The other indirect relationships were not significant.

\section{Path-analysis}

The model showed a very good fit to the data based on information from each indicator: $\chi^{2}=3.81(\mathrm{df}=5)$ with $\mathrm{p}=0.58, \mathrm{CFI}=1.00$, TLI $=1.00$, and RMSEA $=0.0011$. Considering total (i.e., direct and indirect) relationship, physical abuse and physical neglect 
were associated with low levels of insight (for physical abuse: total: $\beta=0.13, \mathrm{SE}=0.06$ and $\mathrm{p}$ $=0.03$, indirect: $\beta=0.05, \mathrm{SE}=0.03$ and $\mathrm{p}=0.13$; for physical neglect: total: $\beta=0.14, \mathrm{SE}=$ 0.07 and $\mathrm{p}=0.03$, indirect: $\beta=0.10, \mathrm{SE}=0.04$ and $\mathrm{p}<0.01)$. Negative symptoms appeared a significant mediator factor between physical abuse and insight $(\beta=0.04, \mathrm{SE}=0.02$ and $\mathrm{p}=$ 0.02). Direct significant relations are presented in the Figure 1.

\section{- FIGURE 1 -}




\section{DISCUSSION}

\section{Principal findings}

This study utilized a community sample of 294 subjects with schizophrenia showing, for the first time, that CT has an influence on the level of insight. Indeed, physical neglect and abuse were indirectly associated with poor levels of insight. The indirect relationship between physical neglect and poor insight was mediated by negative symptoms. Moreover, this study supports the association between positive symptoms and poor insight, as found in a previous investigation (Schrank et al., 2014). The association between depressive symptoms and better levels of insight has previously been shown, being referred to as the "insight paradox" (Belvederi Murri et al., 2015; Misiak et al., 2016a). The relationship between negative symptoms and poor insight, which was stronger than the associations of positive symptoms and depression, is less common in the studies investigating the clinical correlates of insight (Lysaker et al., 2018).

\section{Childhood trauma and poor insight}

As predicted, some of the considered CT variables, namely physical abuse and neglect, were associated with poor insight. However, contrary to our hypotheses, the level of relationship between $\mathrm{CT}$ and poor insight was relatively low $(\beta=0.14$ for physical neglect, $\beta$ $=0.13$ for physical abuse), with negative, but not positive, symptoms mediating this $\underline{\text { relationship. }}$

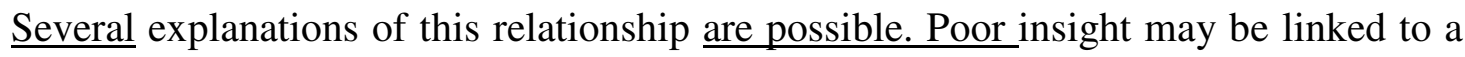
lack of confidence in the outside world, which may be specifically impaired in patients with a CT history (Rokita et al., 2018; Roux et al., 2018). Altered metacognition and theory of mind may also be relevant to such associations (Lysaker et al., 2005; Pos et al., 2015). Surprisingly, positive symptoms were not identified as a clinical mediator between CT and poor insight. However, as in previous studies, positive symptoms are linked both to poor insight, and to a CT history (Misiak et al., 2017, 2016b). Over a number of years, previous studies have addressed the relationship between positive psychotic symptoms and the levels of insight. In 2003, a meta-analysis of 40 studies found a significant, but modest, correlation between positive psychotic symptoms and poor levels of insight (effect-size: $0.25, \mathrm{p}<0.001$ ) (Mintz et al., 2003). In a more recent path-analysis considering different clinical dimensions and insight, the relationship between positive psychotic symptoms and poor insight was also 
significant $(r=0.35)$ (Schrank et al., 2014). In an analysis of the impact of gender on insight, $\underline{\text { Cobo et al. (2016) found significant associations between positive symptoms and all items of }}$ insight $(\mathrm{p}<0.0001)$, in both gender samples.

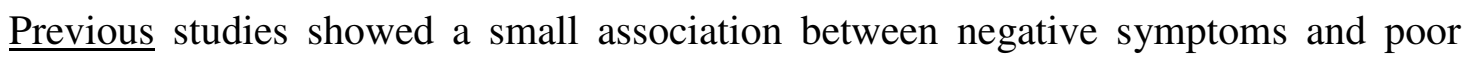
insight, with an effect-size of -0.23 in one meta-analysis (Mintz et al., 2003). Low insight may be conceptualized as a negative symptom, being a "mental withdrawal" from attempting to understand one's own experience (Osatuke et al., 2008). Cognitive dysfunction may be relevant. Indeed, negative symptoms are highly correlated with poor cognitive performances, particularly executive functioning, working memory and episodic memory (Millan et al., 2014). Moreover, among patients with schizophrenia, CT is associated with a higher level of cognitive deficits. Aas et al. (2012) showed that, among patients with schizophrenia, early life stress history was associated with impairments in processing speed and working memory. Moreover, Gil et al. (2009) found that functional and social impairment in schizophrenia is related to physical neglect and emotional abuse and neglect, but not with other CT outcomes. As such, cognitive deficits may also associate with poor insight, including via their association with negative symptoms (Koren et al., 2004; Lysaker et al., 2005).

\section{Childhood trauma and clinical dimensions of schizophrenia}

The present results show that, among subjects with schizophrenia, those with a history of CT display poorer outcomes. The associations of physical neglect and sexual abuse with positive psychotic symptoms have already been shown (Duhig et al., 2015; McCabe et al., 2012). Emotionally adverse experiences, both abuse and neglect, are generally associated with higher levels of depression, and are a significant predictor of suicide in people with schizophrenia (Upthegrove et al., 2017). Such data highlights the clinical relevance of the current results. Emotionally adverse experiences have a specific influence on depression, which is associated with higher levels of insight (Schrank et al., 2014). Thus, patients with a history of emotionally adverse experiences may be a particularly targeted for suicide prevention. The present results indicate that physical abuse and emotional abuse have contrasting impacts on negative symptoms, with a positive association being evident for physical abuse, whilst an inverse correlation is evident for emotional abuse. Such contrasting effects are also evident for depression, which shows a negative association for physical abuse, and a positive association for emotional abuse. This is consistent with an array of different studies showing that emotional and physical adverse experiences can have differential 
consequences. Such data would indicate that measures of adversity and trauma subtypes may be more clinically meaningful than a global indicant (Morgan and Gayer-Anderson, 2016). Other work supports this with Baudin et al. (2017) showing that physical and sexual abuse were specifically associated with a higher risk of psychotic disorders, in comparison to childhood emotional abuse.

Finally, several studies have shown that patients with $\mathrm{CT}$ have a poorer treatment response, including a higher proportion of treatment-resistant schizophrenia (Hassan and De Luca, 2014; Mondelli et al., 2015). A number of studies indicate that early abusive experiences may be associated with alterations in the immune response, which may underlie treatment resistance (e.g., Misiak et al. (2017)). The results of the current study indicate that such resistance may also be linked to poor insight, and lower treatment adherence. Results of $\underline{\text { the present study also suggest that specific treatment of patients with schizophrenia a CT }}$ history, including non-pharmacological (Selten and Cantor-Graae, 2014), should improve several clinical outcomes. The screening of post-traumatic stress disorder (PTSD) is important in routine care of patients with schizophrenia (Brand et al., 2018). Psychotherapy by written emotional disclosure, may significantly improve insight for patients with schizophrenia and $\underline{\text { PTSD }}$ (Swan et al., 2017).

\section{Limitations}

Several limitations deserve discussion. First, the assessment of CT is retrospective, and this design is not exempt from potential uncontrolled recall bias, particularly among patients with persecutory ideas. However, Fisher et al. (2011) have shown that the recall of childhood adversity experiences among individuals with psychosis was stable over time, and not related to the severity of the pathology. Second, the present study analysed cross-sectional data, which preclude causality inference. Thus, although we assumed that the clinical outcomes were mediators between $\mathrm{CT}$ and level of insight, we cannot exclude reverse causation: subjects at higher risk for psychosis, e.g., suffering from early neurodevelopmental impairments, and later suffering from more severe disease, could be overexposed to CT experiences_(Etain et al., 2017). Moreover, we consider the assessment of insight as reflecting a state for each patient, cross-sectionally. However, insight has been reported as partially variable (Ayesa-Arriola et al., 2018), and the relationship between CT and insight may be dynamic. Third, in order to avoid a lack of statistical power in the path-analysis, we considered insight unidimensionally, which is contrary to David's (David, 1990) three- 
dimensional model of insight: the recognition that one has a psychiatric disorder, the ability to relabel unusual mental events (delusions and hallucinations) as pathological, and the recognition of the positive treatment consequences. Finally, for the same reason, other factors that may impact the relationship between CT and insight, such as cognitive factors, have not been included in the path-analysis. Future studies of relationships between CT and insight should utilize cognitive measures.

\section{Conclusion}

Physical abuse and neglect have a significant, but low association with a poor level of insight, and this relationship appeared mediated by the negative symptoms dimension. Moreover, this study supports some associations between the severity of positive and negative symptoms and poor insight, and between depression and higher levels of insight. Further studies should investigate the impact of age at exposure to $\mathrm{CT}$, and the different dimensions of insight. 


\section{REFERENCES}

Aas, M., Steen, N.E., Agartz, I., Aminoff, S.R., Lorentzen, S., Sundet, K., Andreassen, O.A., Melle, I., 2012. Is cognitive impairment following early life stress in severe mental disorders based on specific or general cognitive functioning? Psychiatry Res. 198, 495-500.

Amador, X.F., Flaum, M., Andreasen, N.C., Strauss, D.H., Yale, S.A., Clark, S.C., Gorman, J.M., 1994. Awareness of Illness in Schizophrenia and Schizoaffective and Mood Disorders. Arch. Gen. Psychiatry 51, 826-836.

Andrianarisoa, M., Boyer, L., Godin, O., Brunel, L., Bulzacka, E., Aouizerate, B., Berna, F., Capdevielle, D., Dorey, J.M., Dubertret, C., Dubreucq, J., Faget, C., Gabayet, F., Llorca, P.M., Mallet, J., Misdrahi, D., Rey, R., Richieri, R., Passerieux, C., Schandrin, A., Tronche, A.M., Urbach, M., Vidailhet, P., Schürhoff, F., Fond, G., FACE-SCZ Group, 2017. Childhood trauma, depression and negative symptoms are independently associated with impaired quality of life in schizophrenia. Results from the national FACE-SZ cohort. Schizophr. Res. 185, 173-181.

Ayesa-Arriola, R., Terán, J.M.P., Moríñigo, J.D.L., Rivero, M.C., Setién-Suero, E., AlHalabi, S., Cuesta, M.J., David, A.S., Crespo-Facorro, B., 2018. The dynamic relationship between insight and suicidal behavior in first episode psychosis patients over 3-year followup. Eur. Neuropsychopharmacol. 28, 1161-1172.

Bailey, T., Alvarez-Jimenez, M., Garcia-Sanchez, A.M., Hulbert, C., Barlow, E., Bendall, S., 2018. Childhood Trauma Is Associated With Severity of Hallucinations and Delusions in Psychotic Disorders: A Systematic Review and Meta-Analysis. Schizophr. Bull. 44, 11111122. https://doi.org/10.1093/schbul/sbx161

Baudin, G., Godin, O., Fond, G., Lajnef, M., Aouizerate, B., Berna, F., Brunel, L., Capdevielle, D., Chereau, I., Dorey, J.M., Dubertret, C., Dubreucq, J., Faget, C., Fond, G., Gabayet, F., Laouamri, H., Lancon, C., Le Strat, Y., Tronche, A., Misdrahi, D., Rey, R., Passerieux, C., Schandrin, A., Urbach, M., Llorca, P.-M., Schürhoff, F., FondaMental Academic Centers of Expertise for Schizophrenia (FACE-SZ) collaborators, 2016. Differential effects of childhood trauma and cannabis use disorders in patients suffering from schizophrenia. Schizophr. Res. 175, 161-167.

Baudin, G., Szoke, A., Richard, J.-R., Pelissolo, A., Leboyer, M., Schürhoff, F., 2017. Childhood trauma and psychosis: Beyond the association. Child Abuse Negl. 72, 227-235. https://doi.org/10.1016/j.chiabu.2017.08.003

Belvederi Murri, M., Respino, M., Innamorati, M., Cervetti, A., Calcagno, P., Pompili, M., Lamis, D.A., Ghio, L., Amore, M., 2015. Is good insight associated with depression among patients with schizophrenia? Systematic review and meta-analysis. Schizophr. Res. 162, 234247.

Bentall, R.P., Wickham, S., Shevlin, M., Varese, F., 2012. Do Specific Early-Life Adversities Lead to Specific Symptoms of Psychosis? A Study from the 2007 The Adult Psychiatric Morbidity Survey. Schizophr. Bull. 38, 734-740.

Bernstein, D.P., Stein, J.A., Newcomb, M.D., Walker, E., Pogge, D., Ahluvalia, T., Stokes, J., Handelsman, L., Medrano, M., Desmond, D., Zule, W., 2003. Development and validation of 
a brief screening version of the Childhood Trauma Questionnaire. Child Abuse Negl. 27, 169-190.

Brand, R.M., McEnery, C., Rossell, S., Bendall, S., Thomas, N., 2018. Do trauma-focussed psychological interventions have an effect on psychotic symptoms? A systematic review and meta-analysis. Schizophr. Res. 195, 13-22.

Brohan, E., Elgie, R., Sartorius, N., Thornicroft, G., GAMIAN-Europe Study Group, 2010. Self-stigma, empowerment and perceived discrimination among people with schizophrenia in 14 European countries: the GAMIAN-Europe study. Schizophr. Res. 122, 232-238.

Cobo, J., Nieto, L., Ochoa, S., Pousa, E., Usall, J., Baños, I., González, B., Ruiz, I., Insight Barcelona Research Group, Ruiz, A.I., 2016. Insight and gender in schizophrenia and other psychoses. Psychiatry Res. 243, 268-277.

Cuesta, M.J., Peralta, V., Zarzuela, A., 2000. Reappraising insight in psychosis: Multi-scale longitudinal study. Br. J. Psychiatry 177, 233-240.

David, A.S., 1990. Insight and Psychosis. Br. J. Psychiatry 156, 798-808.

Duhig, M., Patterson, S., Connell, M., Foley, S., Capra, C., Dark, F., Gordon, A., Singh, S., Hides, L., McGrath, J.J., Scott, J., 2015. The prevalence and correlates of childhood trauma in patients with early psychosis. Aust. N. Z. J. Psychiatry 49, 651-659.

Etain, B., Lajnef, M., Henry, C., Aubin, V., Azorin, J.M., Bellivier, F., Bougerol, T., Courtet, P., Gard, S., Kahn, J.P., Passerieux, C., Leboyer, M., FACE-BD Clinical Coordinating Center (FondaMental Foundation), FACE-BD Data Coordinating Center (FondaMental Foundation), FACE-BD Clinical Sites and Principal Collaborators in France, 2017. Childhood trauma, dimensions of psychopathology and the clinical expression of bipolar disorders: A pathway analysis. J. Psychiatr. Res. 95, 37-45.

Fisher, H., Morgan, C., Dazzan, P., Craig, T.K., Morgan, K., Hutchinson, G., Jones, P.B., Doody, G.A., Pariante, C., McGuffin, P., Murray, R.M., Leff, J., Fearon, P., 2009. Gender differences in the association between childhood abuse and psychosis. Br. J. Psychiatry 194, $319-325$.

Fisher, H.L., Craig, T.K., Fearon, P., Morgan, K., Dazzan, P., Lappin, J., Hutchinson, G., Doody, G.A., Jones, P.B., McGuffin, P., Murray, R.M., Leff, J., Morgan, C., 2011. Reliability and comparability of psychosis patients' retrospective reports of childhood abuse. Schizophr. Bull. 37, 546-553.

Gil, A., Gama, C.S., De, D.J., Lobato, M.I., Zimmer, M., Belmonte-de-Abreu, P., 2009. The association of child abuse and neglect with adult disability in schizophrenia and the prominent role of physical neglect. Child Abuse Negl. 33, 618-624.

Guloksuz, S., van Os, J., 2018. The slow death of the concept of schizophrenia and the painful birth of the psychosis spectrum. Psychol. Med. 48, 229-244.

Hassan, A.N., De Luca, V., 2014. The effect of lifetime adversities on resistance to antipsychotic treatment in schizophrenia patients. Schizophr. Res. 161, 496-500. 
Kessler, R.C., McLaughlin, K.A., Green, J.G., Gruber, M.J., Sampson, N.A., Zaslavsky, A.M., Aguilar-Gaxiola, S., Alhamzawi, A.O., Alonso, J., Angermeyer, M., Benjet, C., Bromet, E., Chatterji, S., de Girolamo, G., Demyttenaere, K., Fayyad, J., Florescu, S., Gal, G., Gureje, O., Haro, J.M., Hu, C.-Y., Karam, E.G., Kawakami, N., Lee, S., Lépine, J.-P., Ormel, J., Posada-Villa, J., Sagar, R., Tsang, A., Ustün, T.B., Vassilev, S., Viana, M.C., Williams, D.R., 2010. Childhood adversities and adult psychopathology in the WHO World Mental Health Surveys. Br. J. Psychiatry J. Ment. Sci. 197, 378-385.

Koren, D., Seidman, L.J., Poyurovsky, M., Goldsmith, M., Viksman, P., Zichel, S., Klein, E., 2004. The neuropsychological basis of insight in first-episode schizophrenia: a pilot metacognitive study. Schizophr. Res. 70, 195-202.

Kraan, T.C., Velthorst, E., Themmen, M., Valmaggia, L., Kempton, M.J., McGuire, P., van Os, J., Rutten, B.P.F., Smit, F., de Haan, L., van der Gaag, M., 2018. Child Maltreatment and Clinical Outcome in Individuals at Ultra-High Risk for Psychosis in the EU-GEI High Risk Study. Schizophr. Bull. 44, 584-592.

Lincoln, T.M., Lüllmann, E., Rief, W., 2007. Correlates and Long-Term Consequences of Poor Insight in Patients With Schizophrenia. A Systematic Review. Schizophr. Bull. 33, 1324-1342.

Lysaker, P.H., Carcione, A., Dimaggio, G., Johannesen, J.K., Nicolò, G., Procacci, M., Semerari, A., 2005. Metacognition amidst narratives of self and illness in schizophrenia: associations with neurocognition, symptoms, insight and quality of life. Acta Psychiatr. Scand. 112, 64-71.

Lysaker, P.H., Pattison, M.L., Leonhardt, B.L., Phelps, S., Vohs, J.L., 2018. Insight in schizophrenia spectrum disorders: relationship with behavior, mood and perceived quality of life, underlying causes and emerging treatments. World Psychiatry Off. J. World Psychiatr. Assoc. WPA 17, 12-23.

McCabe, K.L., Maloney, E.A., Stain, H.J., Loughland, C.M., Carr, V.J., 2012. Relationship between childhood adversity and clinical and cognitive features in schizophrenia. J. Psychiatr. Res. 46, 600-607.

McLaughlin, K., Green, J., Gruber, M., Sampson, N.A., Zaslavsky, A., Kessler, R., 2010. Childhood adversities and adult psychiatric disorders in the national comorbidity survey replication II: Associations with persistence of DSM-IV disorders. Arch. Gen. Psychiatry 67, 124-132.

Michel, P., Baumstarck, K., Auquier, P., Amador, X., Dumas, R., Fernandez, J., Lancon, C., Boyer, L., 2013. Psychometric properties of the abbreviated version of the Scale to Assess Unawareness in Mental Disorder in schizophrenia. BMC Psychiatry 13, 1-10.

Millan, M.J., Fone, K., Steckler, T., Horan, W.P., 2014. Negative symptoms of schizophrenia: Clinical characteristics, pathophysiological substrates, experimental models and prospects for improved treatment. Eur. Neuropsychopharmacol. 24, 645-692.

Mintz, A.R., Dobson, K.S., Romney, D.M., 2003. Insight in schizophrenia: a meta-analysis. Schizophr. Res. 61, 75-88. 
Misdrahi, D., Denard, S., Swendsen, J., Jaussent, I., Courtet, P., 2014. Depression in schizophrenia: The influence of the different dimensions of insight. Psychiatry Res. 216, 1216.

Misiak, B., Frydecka, D., Beszłej, J.A., Moustafa, A.A., Tybura, P., Kucharska-Mazur, J., Samochowiec, A., Bieńkowski, P., Samochowiec, J., 2016a. Effects of antipsychotics on insight in schizophrenia: results from independent samples of first-episode and acutely relapsed patients. Int. Clin. Psychopharmacol. 31, 185-191.

Misiak, B., Krefft, M., Bielawski, T., Moustafa, A.A., Sąsiadek, M.M., Frydecka, D., 2017. Toward a unified theory of childhood trauma and psychosis: A comprehensive review of epidemiological, clinical, neuropsychological and biological findings. Neurosci. Biobehav. Rev. 75, 393-406.

Misiak, B., Moustafa, A.A., Kiejna, A., Frydecka, D., 2016b. Childhood traumatic events and types of auditory verbal hallucinations in first-episode schizophrenia patients. Compr. Psychiatry 66, 17-22.

Mondelli, V., Ciufolini, S., Belvederi Murri, M., Bonaccorso, S., Di Forti, M., Giordano, A., Marques, T.R., Zunszain, P.A., Morgan, C., Murray, R.M., Pariante, C.M., Dazzan, P., 2015. Cortisol and Inflammatory Biomarkers Predict Poor Treatment Response in First Episode Psychosis. Schizophr. Bull. 41, 1162-1170.

Morgan, C., Gayer-Anderson, C., 2016. Childhood adversities and psychosis: evidence, challenges, implications. World Psychiatry 15, 93-102.

Morgan, C., Kirkbride, J., Leff, J., Craig, T., Hutchinson, G., McKenzie, K., Morgan, K., Dazzan, P., Doody, G.A., Jones, P., Murray, R., Fearon, P., 2007. Parental separation, loss and psychosis in different ethnic groups: a case-control study. Psychol. Med. 37, 495-503.

Muthén, L., Muthén, B., 2007. Mplus: Statistical analyses with latent variables. User's guide, 6th edition. ed. CA, Los Angeles.

Osatuke, K., Ciesla, J., Kasckow, J.W., Zisook, S., Mohamed, S., 2008. Insight in schizophrenia: a review of etiological models and supporting research. Compr. Psychiatry 49, 70-77.

Paquette, D., Laporte, L., Bigras, M., Zoccolillo, M., 2004. Validation de la version française du CTQ et prévalence de l'histoire de maltraitance. Santé Ment. Au Qué. 29, 201-220.

Paras, M.L., Murad, M.H., Chen, L.P., Goranson, E.N., Sattler, A.L., Colbenson, K.M., Elamin, M.B., Seime, R.J., Prokop, L.J., Zirakzadeh, A., 2009. Sexual Abuse and Lifetime Diagnosis of Somatic Disorders: A Systematic Review and Meta-analysis. JAMA 302, 550561.

Pijnenborg, G.H.M., van Donkersgoed, R.J.M., David, A.S., Aleman, A., 2013. Changes in insight during treatment for psychotic disorders: a meta-analysis. Schizophr. Res. 144, 109117.

Pos, K., Bartels-Velthuis, A.A., Simons, C.J., Korver-Nieberg, N., Meijer, C.J., de Haan, L., 2015. Theory of Mind and attachment styles in people with psychotic disorders, their siblings, and controls. Aust. N. Z. J. Psychiatry 49, 171-180. 
Pousa, E., Ochoa, S., Cobo, J., Nieto, L., Usall, J., Gonzalez, B., Garcia-Ribera, C., Pérez Solà, V., Ruiz, A.-I., Insight Barcelona Research Group, Baños, I., Cobo, J., García-Ribera, C., González, B., Massons, C., Nieto, L., Monserrat, C., Ochoa, S., Pousa, E., Ruiz, A.-I., Ruiz, I., Sanchez-Cabezudo, D., Usall, J., 2017. A deeper view of insight in schizophrenia: Insight dimensions, unawareness and misattribution of particular symptoms and its relation with psychopathological factors. Schizophr. Res. 189, 61-68.

Pries, L.-K., Guloksuz, S., Ten Have, M., de Graaf, R., van Dorsselaer, S., Gunther, N., Rauschenberg, C., Reininghaus, U., Radhakrishnan, R., Bak, M., Rutten, B.P.F., van Os, J., 2018. Evidence That Environmental and Familial Risks for Psychosis Additively Impact a Multidimensional Subthreshold Psychosis Syndrome. Schizophr. Bull. 44, 710-719.

Raffard, S., Trouillet, R., Capdevielle, D., Gely-Nargeot, M.-C., Bayard, S., Larøi, F., Boulenger, J.-P., 2010. La SUMD (Scale to Assess Unawareness of Mental Disorder): validation et adaptation française dans une population de patients souffrant de schizophrénie. Can. J. Psychiatry 55, 523-531.

Read, J., van Os, J., Morrison, A.P., Ross, C.A., 2005. Childhood trauma, psychosis and schizophrenia: a literature review with theoretical and clinical implications. Acta Psychiatr. Scand. 112, 330-350.

Rokita, K.I., Dauvermann, M.R., Donohoe, G., 2018. Early life experiences and social cognition in major psychiatric disorders: A systematic review. Eur. Psychiatry J. Assoc. Eur. Psychiatr. 53, 123-133.

Roux, P., Misdrahi, D., Capdevielle, D., Aouizerate, B., Berna, F., Brunel, L., Chereau, I., Dorey, J.-M., Dubertret, C., Dubreucq, J., Faget-Agius, C., Fonteneau, S., Gabayet, F., Llorca, P.M., Mallet, J., Rey, R., Richieri, R., Schandrin, A., Schürhoff, F., Tessier, A., Vidailhet, P., Passerieux, C., Urbach, M., FACE-SZ Group, 2018. Mediation Analyses of Insight, Quality of Life, Depression, and Suicidality: Results From the FACE-SZ Cohort. J. Clin. Psychiatry 79, pii: $17 \mathrm{~m} 11638$.

Schäfer, I., Fisher, H.L., 2011. Childhood trauma and psychosis - what is the evidence? Dialogues Clin. Neurosci. 13, 360-365.

Schalinski, I., Fischer, Y., Rockstroh, B., 2015. Impact of childhood adversities on the shortterm course of illness in psychotic spectrum disorders. Psychiatry Res. 228, 633-640.

Scher, C.D., Forde, D.R., McQuaid, J.R., Stein, M.B., 2004. Prevalence and demographic correlates of childhood maltreatment in an adult community sample. Child Abuse Negl. 28, $167-180$.

Schrank, B., Amering, M., Hay, A.G., Weber, M., Sibitz, I., 2014. Insight, positive and negative symptoms, hope, depression and self-stigma: a comprehensive model of mutual influences in schizophrenia spectrum disorders. Epidemiol. Psychiatr. Sci. 23, 271-279.

Schürhoff, F., Fond, G., Berna, F., Bulzacka, E., Vilain, J., Capdevielle, D., Misdrahi, D., Leboyer, M., Llorca, P.-M., 2015. A National network of schizophrenia expert centres: An innovative tool to bridge the research-practice gap. Eur. Psychiatry 30, 728-735.

Selten, J.-P., Cantor-Graae, E., 2014. Childhood trauma and the treatment for psychotic disorder. Acta Psychiatr. Scand. 129, 479-480. 
Shevlin, M., Houston, J.E., Dorahy, M.J., Adamson, G., 2008. Cumulative traumas and psychosis: an analysis of the national comorbidity survey and the British Psychiatric Morbidity Survey. Schizophr. Bull. 34, 193-199.

Smith, L.M., Johns, L.C., Mitchell, R., 2017. Characterizing the experience of auditory verbal hallucinations and accompanying delusions in individuals with a diagnosis of bipolar disorder: A systematic review. Bipolar Disord. 19, 417-433.

Smith, T.E., Hull, J.W., Huppert, J.D., Silverstein, S.M., Anthony, D.T., McClough, J.F., 2004. Insight and recovery from psychosis in chronic schizophrenia and schizoaffective disorder patients. J. Psychiatr. Res. 38, 169-176.

Swan, S., Keen, N., Reynolds, N., Onwumere, J., 2017. Psychological Interventions for Posttraumatic Stress Symptoms in Psychosis: A Systematic Review of Outcomes. Front. Psychol. 8 .

Tebeka, S., Le Strat, Y., Hoertel, N., Dubertret, C., 2016. Parental divorce or death during childhood and adolescence and its associations with mental health. J. Nerv. Ment. Dis. 204, 678-685.

Trotta, A., Di Forti, M., Mondelli, V., Dazzan, P., Pariante, C., David, A., Mulè, A., Ferraro, L., Formica, I., Murray, R.M., Fisher, H.L., 2013. Prevalence of bullying victimisation amongst first-episode psychosis patients and unaffected controls. Schizophr. Res. 150, 169175.

Upthegrove, R., Marwaha, S., Birchwood, M., 2017. Depression and Schizophrenia: Cause, Consequence, or Trans-diagnostic Issue? Schizophr. Bull. 43, 240-244.

Varese, F., Smeets, F., Drukker, M., Lieverse, R., Lataster, T., Viechtbauer, W., Read, J., Os, J. van, Bentall, R.P., 2012. Childhood Adversities Increase the Risk of Psychosis: A Metaanalysis of Patient-Control, Prospective- and Cross-sectional Cohort Studies. Schizophr. Bull. 38, 661-671.

Wickrama, K.A.S., Lee, T.-K., O’Neal, C.W., 2015. Stressful Life Experiences in Adolescence and Cardiometabolic Risk Factors in Young Adulthood. J. Adolesc. Health 56, 456-463.

Zhou, Y., Rosenheck, R., Mohamed, S., Zhang, J., Chang, Q., Ou, Y., Sun, B., Ning, Y., He, H., 2015. Insight in inpatients with schizophrenia: relationship to symptoms and neuropsychological functioning. Schizophr. Res. 161, 376-381. 


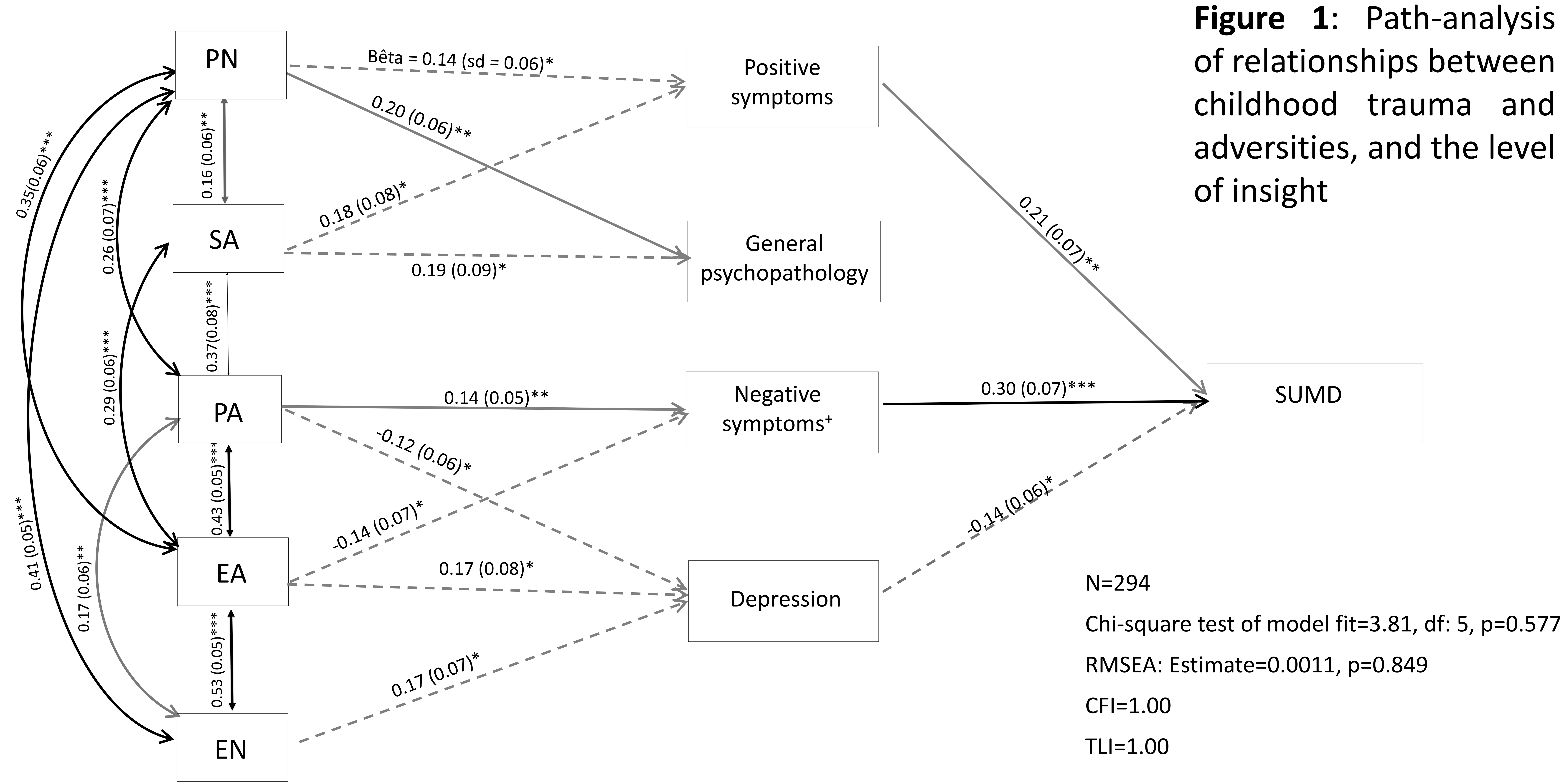

Abbreviations: CFI: Comparative Fit Index, EA: Emotional Abuse, EN: Emotional Neglect, PA: Physical Abuse; PANSS: Positive And Negative Symptoms Scale, PN: Physical Neglect, RMSEA: Root Mean square of Approximation, SA: Sexual Abuse, sd: standard-deviation; SUMD: Scale to Assess Unawareness of Mental Disorder, TLI: Tucker-Lewis Index.
${ }^{+}:$negative symptoms were significant mediator between PA and SUMD

$* * *<0.001$ ** $0.001-0.01$ * $0.01-0.05$ 
Table 1. Main sociodemographic and clinical characteristics of the sample of 294 patients

\begin{tabular}{|l|c|}
\hline & Mean (SD) or N $(\%)$ \\
\hline Age & $32.1( \pm 9.8)$ \\
\hline Sex (men) & $218(73.8 \%)$ \\
\hline SUMD $^{1}$ & $26.3( \pm 24.6)$ \\
\hline Duration of the disease (years) & $10.1( \pm 8.0)$ \\
\hline PANSS & $71.0( \pm 18.9)$ \\
\hline CTQ total score & $40.9( \pm 10.8)$ \\
\hline CTQ sub-scores: & \\
Emotional abuse & $9.1( \pm 4.0)$ \\
Emotional negligence & $11.6( \pm 4.1)$ \\
Physical abuse & $6.5( \pm 2.7)$ \\
Physical negligence & $7.7( \pm 2.7)$ \\
Sexual abuse & $6.0( \pm 2.4)$ \\
\hline
\end{tabular}

Abbreviations: PANSS: Positive And Negative Symptoms Scale; CTQ: Childhood Trauma Questionnaire; SUMD: Scale to Assess Unawareness of Mental Disorder.

${ }^{1}$ SUMD was calculated using the mean scores of all items, which were linearized on a scale 0 $\underline{100 .}$ 